\title{
Comparison of the Clinical Outcomes Between Nebulized and Systemic Corticosteroids in the Treatment of Acute Exacerbation of COPD in China (CONTAIN Study): A Post Hoc Analysis
}

This article was published in the following Dove Press journal:

International Journal of Chronic Obstructive Pulmonary Disease

\author{
Yahong Chen ${ }^{1, *}$ \\ Yang Liu, ${ }^{2, *}$ \\ Jing Zhang I,* $^{*}$ \\ Wanzhen Yao' \\ Jingping Yang ${ }^{3}$ \\ Fan $\mathrm{Li}^{4}$ \\ Liwen $\mathrm{Lu}^{5}$ \\ Jinping Zheng $\mathbb{B D}^{6}$ \\ Xiaowen $\mathrm{Han}^{7}$ \\ Jin-fu Xu (D) ${ }^{2}$
}

'Department of Respiratory Medicine, Peking University Third Hospital, Beijing, People's Republic of China; ${ }^{2}$ Department of Respiratory and Critical Care Medicine, Shanghai Pulmonary Hospital, Tongji University School of Medicine, Shanghai, People's Republic of China; ${ }^{3}$ Department of Respiratory and Critical Care Medicine, Baogang Hospital, Third Affiliated Hospital of Inner Mongolia Medical College, Third School of Clinical Medicine, Inner Mongolia Regional Medical Center, Baotou, People's Republic of China; ${ }^{4}$ Department of Respiratory Medicine, Shanghai Songjiang District Central Hospital, Shanghai, People's Republic of China; ${ }^{5}$ Department of Respiratory Medicine, Shanghai Fengxian District Central Hospital, Shanghai, People's Republic of China; 'State Key Laboratory of Respiratory Disease,

National Clinical Research Center of Respiratory Disease, Guangzhou Institute of Respiratory Health, First Affiliated Hospital of Guangzhou Medical University, Guangzhou, People's Republic of China; ${ }^{7}$ Department of Respiratory Medicine, Hebei Provincial People's Hospital, Shijiazhuang, People's Republic of China

*These authors contributed equally to this work

Correspondence: Jin-fu Xu

Email jfxucn@I63.com
Background and Objective: Although corticosteroids have been widely used in the treatment of acute exacerbation of chronic obstructive pulmonary disease (AECOPD), few studies have evaluated the effectiveness of nebulized corticosteroids (NCS), systemic corticosteroids (SCS), and NCS plus SCS in the management of AECOPD in China. This study aimed to evaluate the effectiveness of NCS, SCS, and NCS plus SCS in Chinese patients with AECOPD.

Patients and Methods: This was a real-world study of AECOPD patients at 43 sites from January to September 2014. During hospitalization, patients treated with nebulized budesonide (NCS group, $n=1091$ ), SCS (SCS group, $n=709$ ), or both (NCS+SCS group, $n=1846$ ) were included. Propensity score matching (PSM) and subgroup analyses were performed. The primary outcomes were the length of hospital stay, mortality, and change in arterial blood gases from baseline.

Results: Multivariable analysis showed that the three treatments at the same severity of AECOPD were not significantly different regarding intubation rates, rates of pneumonia improvement at discharge, rates of new-onset pneumonia in hospital, and mortality. Following PSM, NCS+SCS was associated with greater length of hospital stay than both NCS and SCS (in patients without respiratory failure [RF, $P<0.001]$ and with type I RF $[P=0.022]$ ), and more hospitalization costs than the other two treatments (in patients without $\mathrm{RF}[P<0.001]$ ).

Conclusion: NCS is effective for patients with AECOPD, which may be an alternative treatment option. Further clinical trials are urgently needed to better understand the efficacy of NCS, SCS, and NCS+SCS in AECOPD management in China.

Keywords: acute exacerbation, chronic obstructive pulmonary disease, clinical outcomes, corticosteroids

\section{Introduction}

Chronic obstructive pulmonary disease (COPD) is a leading cause of morbidity and mortality. The number of patients with COPD in China increased from 32.4 million in 1990 to 99.9 million in 2015. ${ }^{1,2}$ COPD resulted in 910,809 deaths in China in 2013, accounting for $31.1 \%$ of all deaths from COPD worldwide. ${ }^{1}$

Acute exacerbation of COPD (AECOPD) is characterized by increases in a patient's dyspnea, cough, and/or sputum production. ${ }^{3}$ The Global Initiative for Chronic Obstructive Lung Disease (GOLD) defines an acute exacerbation as 
an acute event characterized by a worsening of the patients' respiratory symptoms that is beyond normal dayto-day variations and leads to a change in medication. ${ }^{3}$

Acute exacerbation is common in patients with COPD and is associated with increased morbidity, mortality, and healthcare costs. ${ }^{4,5}$

GOLD attempted to provide evidence-based international guidelines for the treatment of AECOPD, ${ }^{6}$ aiming to minimize the impact of AECOPD and prevent future events. ${ }^{6}$ Systemic corticosteroids (SCS), bronchodilators, and antibacterial agents can be used for managing AECOPD. ${ }^{3,7}$ The use of SCS for AECOPD is recommended since they improve symptoms and lung function, shorten the length of hospital stay and lower the readmission rate. ${ }^{6}$ Nevertheless, the frequent use of SCS can result in osteoporosis, thinning of the skin, cataract formation, myopathy, and glucose intolerance. ${ }^{8,9}$ Several studies suggested that inhaled corticosteroids (ICS) can be safe and effective in managing AECOPD because of their high degree of topical anti-inflammatory activity with limited systemic effect. ${ }^{10-12}$ ICS are found to improve symptoms, lung function, and quality of life and reduce exacerbations of COPD. ${ }^{13}$ One study from China demonstrated that ICS have a similar efficacy than SCS. ${ }^{14}$ Nevertheless, those studies included mostly mild AECOPD patients, which do not reflect hospitalized AECOPD patients in a realworld setting.

Therefore, we designed a post hoc study to evaluate the effectiveness of nebulized corticosteroids (NCS), SCS, and $\mathrm{NCS}+\mathrm{SCS}$ therapies in the management of AECOPD in China.

\section{Patients and Methods}

The original study was a retrospective, multicenter, noninterventional study (ClinicalTrials.gov NCT02051166) that was carried out at 43 sites located in 22 provinces across China from January 2014 to September 2014. The primary objective was to investigate the treatment patterns of AECOPD in hospitalized patients in China. ${ }^{15}$ The outcomes of the original study were the percentage of patients receiving glucocorticoids by different routes of administration, doses and duration, mortality, and the mean length of hospitalization. ${ }^{15}$ Forty sites $(93.0 \%)$ were tertiary hospitals located in major cities. The original study and post hoc analyses were approved by the local ethics committees (Appendix 1) and conducted in accordance with the Declaration of Helsinki. Treatments were formulated according to local clinical practice, which presented a minimal risk to the patients. Informed consent was waived by the local ethics committees, as data were collected retrospectively from patients who have been treated and discharged from the hospital. Data for the study was provided by each site via electronic and paper case report forms (CRFs). The study database was used for the present post hoc analysis, which is the first multicenter, real-world, non-interventional study in China to report the possible outcome difference(s) among different treatments in managing hospitalized AECOPD patients. The data accessed complied with relevant data protection and privacy regulations, as per Chinese laws and regulations and the Good Clinical Practice.

\section{Study Populations}

Eligible patients were $\geq 40$ years of age, diagnosed with COPD according to the GOLD 2013 criteria for at least three months before acute exacerbation, were hospitalized after September 2013 due to AECOPD (patients could be included if they were hospitalized after September 2013 and were still hospitalized in January 2014), and received nebulized budesonide (NCS group), oral or intravenous SCS (SCS group), or both treatments sequentially or concurrently (NCS+SCS group). Those hospitalized patients were considered as moderate-to-severe AECOPD patients, judged by the physicians. Patients were excluded if they had participated in a trial within 3 months before enrollment, had aggravated AECOPD during the enrollment period, and were discharged without treatment, or the primary diagnosis was not AECOPD.

\section{Outcomes}

The primary outcomes were the length of hospital stay, mortality during hospitalization, and change in arterial blood gases $\left(\mathrm{PaO}_{2}, \mathrm{PaCO}_{2}, \mathrm{SaO}_{2}\right.$, and $\left.\mathrm{pH}\right)$ from baseline. The secondary outcomes were the intubation rates, rates of pneumonia improvement at discharge (defined as the number of patients whose pneumonia at enrollment or during hospitalization was cured at discharge), rates of new-onset pneumonia during hospitalization, and AECOPD hospitalization costs. The data about pneumonia were collected from medical records. Patients were analyzed according to the respiratory failure (RF) type. Type I RF was defined as $\mathrm{PaO}_{2}<60 \mathrm{mmHg}$, with a normal or low $\mathrm{PaCO}_{2}$. Type II $\mathrm{RF}$ was defined as $\mathrm{PaO}_{2}<60 \mathrm{mmHg}$ and $\mathrm{PaCO}_{2}>50 \mathrm{mmHg}$. 


\section{Statistical Analysis}

Continuous data are presented as mean \pm standard deviation (SD) and were compared by one-way analysis of variance (ANOVA). Categorical data are presented as counts and percentages, and the chi-square test or Fisher's exact test was performed for group comparisons. Univariable and multivariable logistic regression analyses were used to detect if the different treatments were associated with the outcomes. Multivariable linear regression was performed to detect if the different treatments were associated with lengths of hospital stay and improvement of $\mathrm{PaO}_{2}, \mathrm{PaCO}_{2}$, $\mathrm{SaO}_{2}$, and $\mathrm{pH}$. A survival data analysis method (subdistribution hazard regression for competing risk) was used to compare the time to discharge among the three groups. The competing risk introduced by death with a shorter time duration representing an opposite effect against discharge was excluded by using this model. Propensity score matching (PSM) was used to match data and to analyze the differences after matching. Variables matched were demographics (sex and age) and disease characteristics (RF, acidosis, duration of COPD, and duration of AECOPD). Conditional on the NCS group, we used logistics regression to create two propensity scores for the NCS+SCS and SCS groups, respectively. After that, we used these two scores together to construct matched samples by applying the strata match method. The interval was set as 0.25 multiplied by SD of the two scores. All matched patients were kept to accommodate the data loss of the matching across the three groups. Statistical analyses were performed using SAS 9.4 (SAS Institute Inc., Cary, NC, USA). A two-tailed $P<0.05$ indicated statistical significance.

\section{Results \\ Demographics and Baseline Characteristics}

Overall, 5067 inpatients with AECOPD were first included, of which 1421 were excluded from the final analysis because of no corticosteroid treatment during AECOPD, NCS other than budesonide, budesonide add-on to another NCS, NCS given via other methods than nebulization; or SCS delivered via other means than orally or intravenously. Finally, 3646 patients who received NCS $(n=1091)$, NCS+SCS $(n=1846)$, or SCS $(n=709)$ for treatment of AECOPD were included in the post hoc analysis (Figure 1).

Across the three groups, most patients were male (range $72.4 \%$ to $79.5 \%$ ), and the mean age ranged from 72.9 to 73.2 years. Most patients had a history of smoking (ie, current or former smokers) (range, $66.0 \%$ to $69.1 \%$ ). The duration of

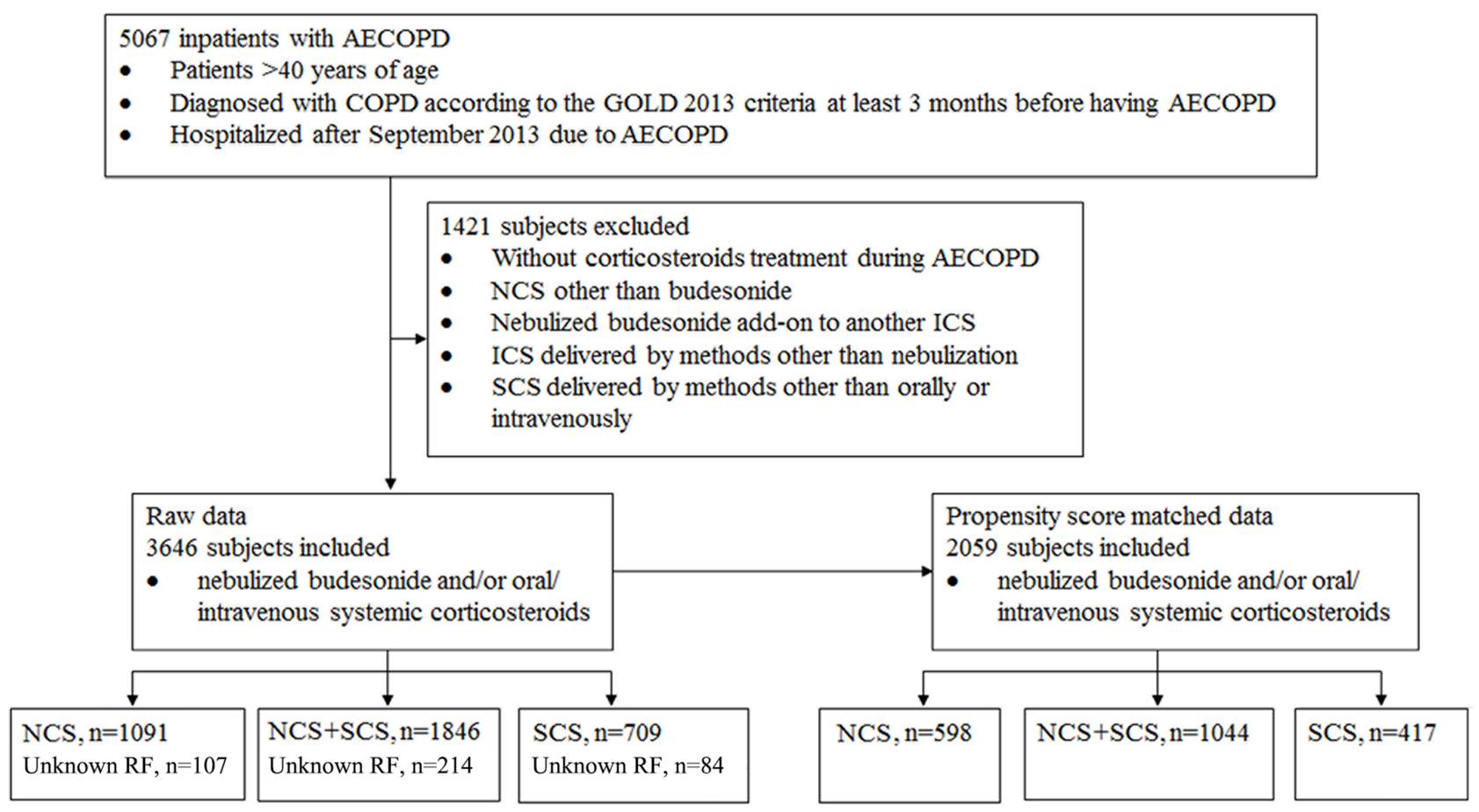

Figure I Flow diagram of the patient selection process for post hoc analysis.

Abbreviations: ICS, inhaled corticosteroids; NCS, nebulized corticosteroids (budesonide); SCS, systemic corticosteroids; NCS+SCS, combination of NCS and SCS therapies; AECOPD, acute exacerbation of chronic obstructive pulmonary disease; RF, respiratory failure. 
Table I Baseline Characteristics of Hospitalized AECOPD Patients Treated with NCS, SCS, or NCS+SCS Before Propensity Score Matching

\begin{tabular}{|c|c|c|c|c|}
\hline \multirow[t]{2}{*}{ Variables } & NCS & SCS & NCS+SCS & \multirow[t]{2}{*}{$P$} \\
\hline & $(N=1091)$ & $(N=709)$ & $(N=1846)$ & \\
\hline Age (years) & $72.9 \pm 9.79$ & $72.9 \pm 9.59$ & $73.2 \pm 9.27$ & $<0.001^{\mathrm{a}}$ \\
\hline $\begin{array}{l}\text { Sex } \\
\qquad \text { Male } \\
\text { Female }\end{array}$ & $\begin{array}{l}790(72.4 \%) \\
301(27.6 \%)\end{array}$ & $\begin{array}{l}564 \text { (79.5\%) } \\
145 \text { (20.5\%) }\end{array}$ & $\begin{array}{l}\text { I } 403 \text { (76.0\%) } \\
443(24.0 \%)\end{array}$ & $0.220^{\mathrm{b}}$ \\
\hline $\begin{array}{l}\text { BMI }\left(\mathrm{kg} / \mathrm{m}^{2}\right) \\
\text { Duration of COPD (years) } \\
\text { Duration of AECOPD (days) } \\
\text { Pneumonia at enrollment }\end{array}$ & $\begin{array}{l}22.2 \pm 3.75 \\
9.2 \pm 9.06 \\
19.0 \pm 48.09 \\
264(24.2 \%)\end{array}$ & $\begin{array}{l}21.8 \pm 3.38 \\
10.7 \pm 9.19 \\
17.9 \pm 34.01 \\
172(24.3 \%)\end{array}$ & $\begin{array}{l}22.2 \pm 3.32 \\
10.1 \pm 9.70 \\
17.0 \pm 35.71 \\
473(25.6 \%)\end{array}$ & $\begin{array}{l}<0.001^{\mathrm{a}} \\
<0.001^{\mathrm{a}} \\
<0.001^{\mathrm{a}} \\
0.919^{\mathrm{b}}\end{array}$ \\
\hline $\begin{array}{l}\text { First monitor index } \\
\text { First } \mathrm{PaO}_{2}(\mathrm{mmHg}) \\
\text { First } \mathrm{PaCO}_{2}(\mathrm{mmHg}) \\
\text { First } \mathrm{SaO}_{2}(\%) \\
\text { First } \mathrm{pH}\end{array}$ & $\begin{array}{l}74.4 \pm 26.50 \\
48.7 \pm 15.36 \\
91.3 \pm 9.20 \\
7.4 \pm 0.06\end{array}$ & $\begin{array}{l}79.8 \pm 30.89 \\
50.9 \pm 16.98 \\
92.1 \pm 8.72 \\
7.4 \pm 0.07\end{array}$ & $\begin{array}{l}79.9 \pm 30.93 \\
51.5 \pm 16.90 \\
92.6 \pm 7.44 \\
7.4 \pm 0.06\end{array}$ & $\begin{array}{l}<0.001^{\mathrm{a}} \\
<0.001^{\mathrm{a}} \\
<0.001^{\mathrm{a}} \\
<0.001^{\mathrm{a}}\end{array}$ \\
\hline $\begin{array}{l}\text { Smoking } \\
\text { Smoking status } \\
\text { Never smoked } \\
\text { Current smokers } \\
\text { Former smokers } \\
\text { Missing data } \\
\text { Smoking duration (years) } \\
\text { Smoking amount (packets/year) }\end{array}$ & $\begin{array}{l}350(32.1 \%) \\
276(25.3 \%) \\
456(41.8 \%) \\
9(0.8 \%) \\
35.3 \pm 13.19 \\
58.3 \pm 93.45\end{array}$ & $\begin{array}{l}229(32.3 \%) \\
163(23.0 \%) \\
305(43.0 \%) \\
12(1.7 \%) \\
34.3 \pm 12.17 \\
66.8 \pm 115.20\end{array}$ & $\begin{array}{l}547(29.6 \%) \\
462(25.0 \%) \\
814(44.1 \%) \\
23(1.2 \%) \\
35.0 \pm 12.82 \\
63.0 \pm 96.59\end{array}$ & $\begin{array}{l}0.305^{\mathrm{b}} \\
\\
<0.001^{\mathrm{a}} \\
<0.001^{\mathrm{a}}\end{array}$ \\
\hline $\begin{array}{l}\text { Living environment } \\
\text { Long-term passive smoking } \\
\text { Long-term exposure to occupational dust and gas fumes } \\
\text { Air pollution } \\
\text { Damp, cold or foggy } \\
\text { None of the above }\end{array}$ & $\begin{array}{l}91(8.3 \%) \\
74(6.8 \%) \\
4 I 1(37.7 \%) \\
106(9.7 \%) \\
518(47.5 \%)\end{array}$ & $\begin{array}{l}53(7.5 \%) \\
41(5.8 \%) \\
255(36.0 \%) \\
166(23.4 \%) \\
311(43.9 \%)\end{array}$ & $\begin{array}{l}143(7.7 \%) \\
105(5.7 \%) \\
655(35.5 \%) \\
207(11.2 \%) \\
925(50.1 \%)\end{array}$ & $\begin{array}{l}0.650^{\mathrm{b}} \\
0.359^{\mathrm{b}} \\
0.139^{\mathrm{b}} \\
0.08 \mathrm{I}^{\mathrm{b}} \\
0.090^{\mathrm{b}}\end{array}$ \\
\hline $\begin{array}{l}\text { Comorbidities } \\
\text { Mean total dose }(\mathrm{mg}) \\
\text { Mean daily dose }(\mathrm{mg}) \\
\text { Mean treatment duration (days) }\end{array}$ & $\begin{array}{l}177(16.2 \%) \\
33.0 \pm 25.16 \\
3.8 \pm 1.77 \\
8.7 \pm 5.11\end{array}$ & $\begin{array}{l}137(19.3 \%) \\
367.9 \pm 364.72^{*} \\
49.9 \pm 38.34 * \\
7.9 \pm 5.10\end{array}$ & $\begin{array}{l}366(19.8 \%) \\
36.9 \pm 70.50 / 442.2 \pm 482.75^{*} \\
3.1 \pm 3.07 / 61.1 \pm 61.36^{*} \\
\mid 2.3 \pm 8.29 / 7.8 \pm 5.44\end{array}$ & $\begin{array}{l}- \\
- \\
- \\
-\end{array}$ \\
\hline
\end{tabular}

Notes: Data were summarized as mean \pm standard deviation for continuous variables and $\mathrm{n}$ (percentage) for categorical data. ${ }^{\mathrm{a}}$ One-way analysis of variance. ${ }^{\mathrm{b}} \mathrm{Chi}-\mathrm{square}$ test. *Equivalent prednisone dose.

Abbreviations: NCS, nebulized corticosteroids; SCS, systemic corticosteroids; AECOPD, acute exacerbation of chronic obstructive pulmonary disease; BMI, body mass index.

smoking ranged from 34.3 to 35.3 years, and the range of pack-year was 58.3 to 66.8 . Almost $50 \%$ of the patients (range, $43.9 \%$ to $50.1 \%$ ) in each group had not experienced long-term passive smoking, occupational dust and gas fumes, air pollution, damp or foggy living environments (Table 1).

\section{Clinical Outcomes}

The SCS group was associated with the highest rate of mortality and the largest improvement in $\mathrm{PaO}_{2}$. The NCS
+SCS group was associated with the longest hospital stay and the highest hospitalization costs compared with the other groups. The NCS group had the largest improvements in $\mathrm{PaCO}_{2}$ and $\mathrm{SaO}_{2}$. No change in $\mathrm{pH}$ was observed among the three groups (Table 2).

\section{Multivariable Regression Analysis}

After adjusting for age, sex, height, weight, duration of COPD, duration of initial AECOPD, and baseline $\mathrm{PaO}_{2}$, 
Table 2 Clinical Outcomes of Hospitalized AECOPD Patients Treated with NCS, SCS, or NCS+SCS Before Propensity Score Matching

\begin{tabular}{|c|c|c|c|c|}
\hline \multirow[t]{2}{*}{ Variables } & NCS & SCS & NCS+SCS & \multirow[t]{2}{*}{$\boldsymbol{P}$} \\
\hline & $(N=1091)$ & $(\mathrm{N}=709)$ & $(N=1846)$ & \\
\hline \multicolumn{5}{|l|}{ Primary outcomes } \\
\hline Length of hospital stay (days) & $11.8 \pm 6.84$ & $12.0 \pm 5.10$ & $13.3 \pm 6.46$ & $<0.00 \mathrm{I}^{\mathrm{a}}$ \\
\hline Mortality & II (I.0\%) & $15(2.1 \%)$ & $31(1.7 \%)$ & $<0.001^{\mathrm{b}}$ \\
\hline \multicolumn{5}{|l|}{ Improvement monitor index } \\
\hline Improvement of $\mathrm{PaO}_{2}(\mathrm{mmHg})$ & $5.9 \pm 31.46$ & $6.4 \pm 44.01$ & $5.5 \pm 37.07$ & $0.001^{\mathrm{a}}$ \\
\hline Improvement of $\mathrm{PaCO}_{2}(\mathrm{mmHg})$ & $-5.3 \pm 14.42$ & $-4.9 \pm 16.78$ & $-4.3 \pm 15.30$ & $0.001^{\mathrm{a}}$ \\
\hline Improvement of $\mathrm{SaO}_{2}(\%)$ & $4.8 \pm 11.82$ & $3.9 \pm 12.92$ & $2.9 \pm 8.45$ & $<0.001^{\mathrm{a}}$ \\
\hline Improvement of $\mathrm{pH}$ & $0.0 \pm 0.07$ & $0.0 \pm 0.08$ & $0.0 \pm 0.07$ & $<0.001^{\mathrm{a}}$ \\
\hline \multicolumn{5}{|l|}{ Secondary outcomes } \\
\hline Intubation rate & $32(2.9 \%)$ & $15(2.1 \%)$ & $53(2.9 \%)$ & $0.147^{b}$ \\
\hline New onset pneumonia in hospital & $21(1.9 \%)$ & $20(2.8 \%)$ & $49(2.7 \%)$ & $0.966^{\mathrm{b}}$ \\
\hline Rate of pneumonia improvement at discharge & $24 \mid(22.1 \%)$ & $162(22.8 \%)$ & $456(24.7 \%)$ & $0.108^{\mathrm{b}}$ \\
\hline Hospitalization expense (CNY) & $14,668.6 \pm 15,563.76$ & $|4,6| 4.4 \pm 10,242.93$ & $17,905.4 \pm 15,503.07$ & $<0.001^{\mathrm{a}}$ \\
\hline
\end{tabular}

Notes: Data were summarized as mean \pm standard deviation for continuous variables and $\mathrm{n}$ (percentage) for categorical data. ${ }^{\#}$ Rate of pneumonia improvement at discharge was defined as the reduction in the incidence of pneumonia from baseline to discharge. ${ }^{a}$ One-way analysis of variance. ${ }^{b} \mathrm{Chi}$-square test.

Abbreviations: NCS, nebulized corticosteroids; SCS, systemic corticosteroids; AECOPD, acute exacerbation of chronic obstructive pulmonary disease; CNY, China Yuan.

$\mathrm{PaCO}_{2}, \mathrm{SaO}_{2}$, and $\mathrm{pH}$, multivariable logistic regression analysis with treatment as the only independent variable (adjusted analysis) showed that the three treatment groups at the same severity of AECOPD were similar with respect to intubation rate, rate of pneumonia improvement at discharge, rate of new-onset pneumonia in the hospital, and mortality ( $P \geq 0.05$ ) (Figure 2$)$.

The final general linear model, adjusted for age, sex, height, weight, duration of COPD, duration of initial AECOPD, initial $\mathrm{PaO}_{2}, \mathrm{PaCO}_{2}, \mathrm{SaO}_{2}$, and $\mathrm{pH}$ showed that $\mathrm{NCS}+\mathrm{SCS}$ therapies were associated with longer length of hospital stay at the same severity grade of AECOPD compared with NCS therapy $(P<0.001$, $P=0.012$, and $P=0.028$, respectively). In AECOPD patients without RF, treatment with $\mathrm{NCS}+\mathrm{SCS}$ was associated with larger improvements in $\mathrm{PaO}_{2}$ and $\mathrm{SaO}_{2}$ compared with NCS $(P=0.001, P=0.006$, respectively), and treatment with SCS was associated with larger improvement in $\mathrm{PaO}_{2}$ compared with $\mathrm{NCS}(P=0.038)$. In AECOPD patients with type I RF, treatment with NCS+SCS was associated with larger improvement in $\mathrm{PaCO}_{2}$ compared with NCS $(P=0.016)$ (Figure 3$)$.

\section{Sub-Distribution Hazard Regression for Competing Risk of Death and Discharge}

After adjustment for age, sex, height, weight, duration of COPD, duration of initial AECOPD, and baseline $\mathrm{PaO}_{2}$,
$\mathrm{PaCO}_{2}, \mathrm{SaO}_{2}$, and $\mathrm{pH}$, the model with treatment as the only independent variable showed that the NCS+SCS group had longer median hospital stays compared with the NCS group in AECOPD patients at the same severity grade ( $P<0.001, P=0.016$, and $P<0.001$, respectively), and the SCS group had longer median hospital stays compared with the NCS group in AECOPD patients with type II RF $(P<0.048)$ (Supplemental Figure 1).

\section{Propensity Score Matching Analysis}

Following PSM, differences in some baseline characteristics and clinical outcomes were no longer significant except for baseline $\mathrm{PaO}_{2}(P=0.030)$ and baseline $\mathrm{PaCO}_{2}$ $(P=0.001)$ (Supplemental Table 1). The NCS+SCS group was associated with a significantly greater length of hospital stay in patients without RF $(P<0.001)$ (Table 3$)$ and in patients with type I RF $(P=0.022)$ (Table 4). Meanwhile, NCS+SCS had greater hospitalization costs $(17,669.9$ CYN) compared with NCS (13,268.9 CYN) and SCS $(13,752.9 \mathrm{CYN})$ in AECOPD patients without RF $(P<0.001)$ (Table 3).

\section{Discussion}

SCSs are considered as a mainstay of AECOPD treatment, but they have many side effects such as hyperglycemia, hypertension, osteoporosis, peptic ulcer, and immunosuppression. For elderly patients with AECOPD, 


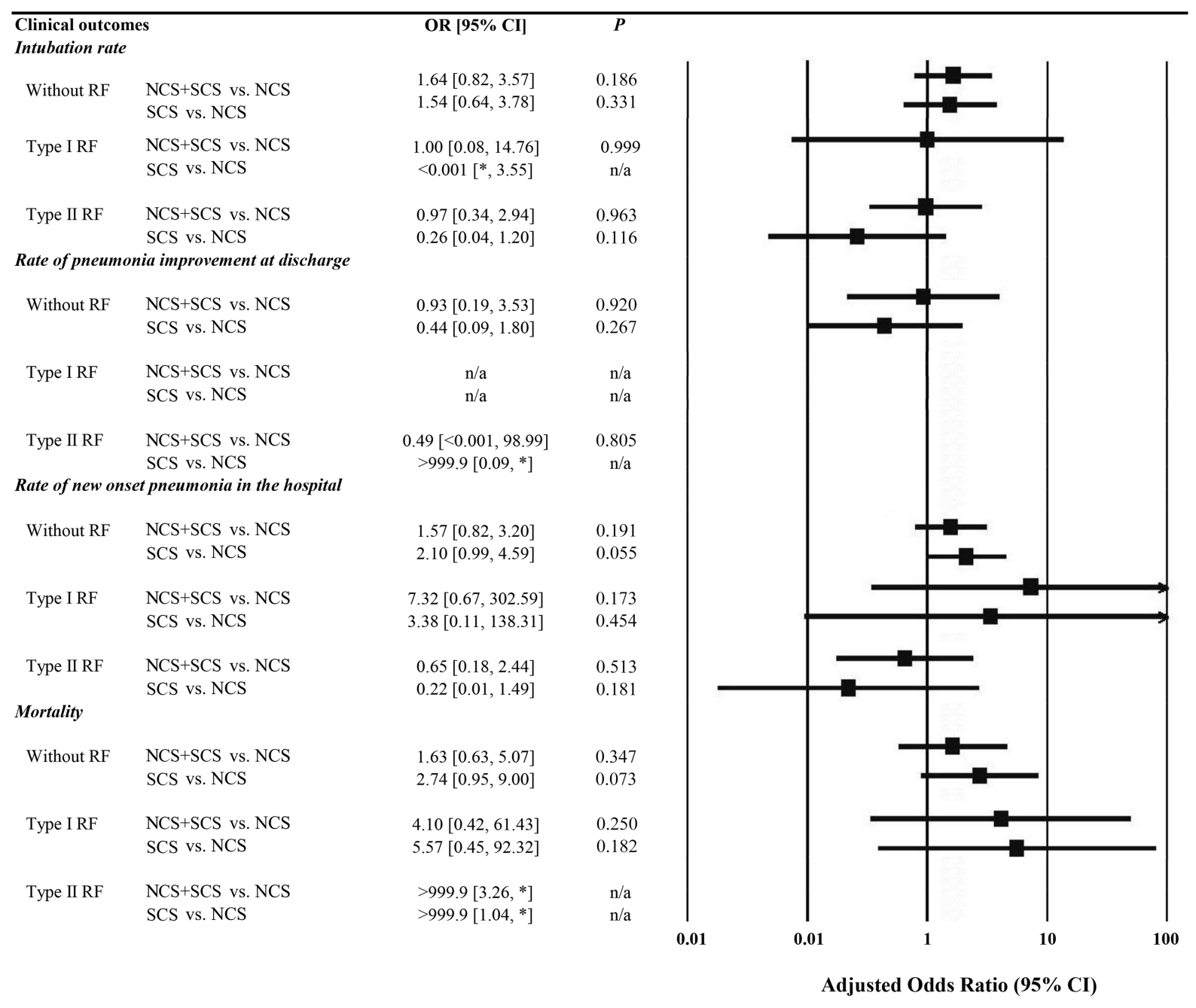

Figure 2 Frequency and logistic regression results for categorical data of clinical outcomes. NCS was used as the reference; adjusted odds ratio was adjusted by age, sex, height, weight, duration of COPD, duration of initial AECOPD, $\mathrm{PaO}_{2}$ at the first time, $\mathrm{PaCO}_{2}$ at the first time, $\mathrm{SaO}_{2}$ at the first time and $\mathrm{pH}$ at the first time. OR values of some clinical outcomes were very large or small, and the exact value could not be obtained, *was used instead.

Abbreviations: NCS, nebulized corticosteroids (budesonide); SCS, systemic corticosteroids; NCS+SCS, combination of NCS and SCS therapies;RF, respiratory failure; OR, odds ratio; n/a, not assessed.

more attention needs to be paid to these side effects because of the high frequency of comorbidities, especially because immunosuppression often induces infections or aggravates pre-existing infections. Some observational studies suggest that low doses of SCSs may be superior to high doses in patients with AECOPD, ${ }^{16-18}$ even though high doses are more commonly used. ${ }^{19}$ In a single-center retrospective cohort study, 665 AECOPD patients were divided into three cumulative dose range groups (low: $\leq 250 \mathrm{mg}$ prednisone equivalents, moderate: 251 to $500 \mathrm{mg}$, and high: $\geq 501 \mathrm{mg}$ ) and there were no statistically significant increases in length of hospital stay and readmission rates when the systemic corticosteroid doses increased, but the rate of impaired blood glucose levels obviously increased with SCS dose. ${ }^{20}$ In addition, those studies mostly included patients with mild AECOPD, and data are lacking regarding moderate and severe AECOPD.

ICSs may be a suitable solution to balance the benefits and side effects of SCS because of lower rates of side effects. Randomized controlled trials showed that nebulized budesonide alone might be a suitable alternative for AECOPD treatment. Maltais et $\mathrm{al}^{21}$ observed that the difference in forced expiratory volume in one second (FEV1) between nebulized budesonide ( $2 \mathrm{mg}$, q $6 \mathrm{~h}$ ) and oral prednisolone ( $30 \mathrm{mg}, \mathrm{q} 12 \mathrm{~h}$ ) was not significant in the treatment of non-acidotic AECOPD. A recent Chinese study also showed that there were no significant 


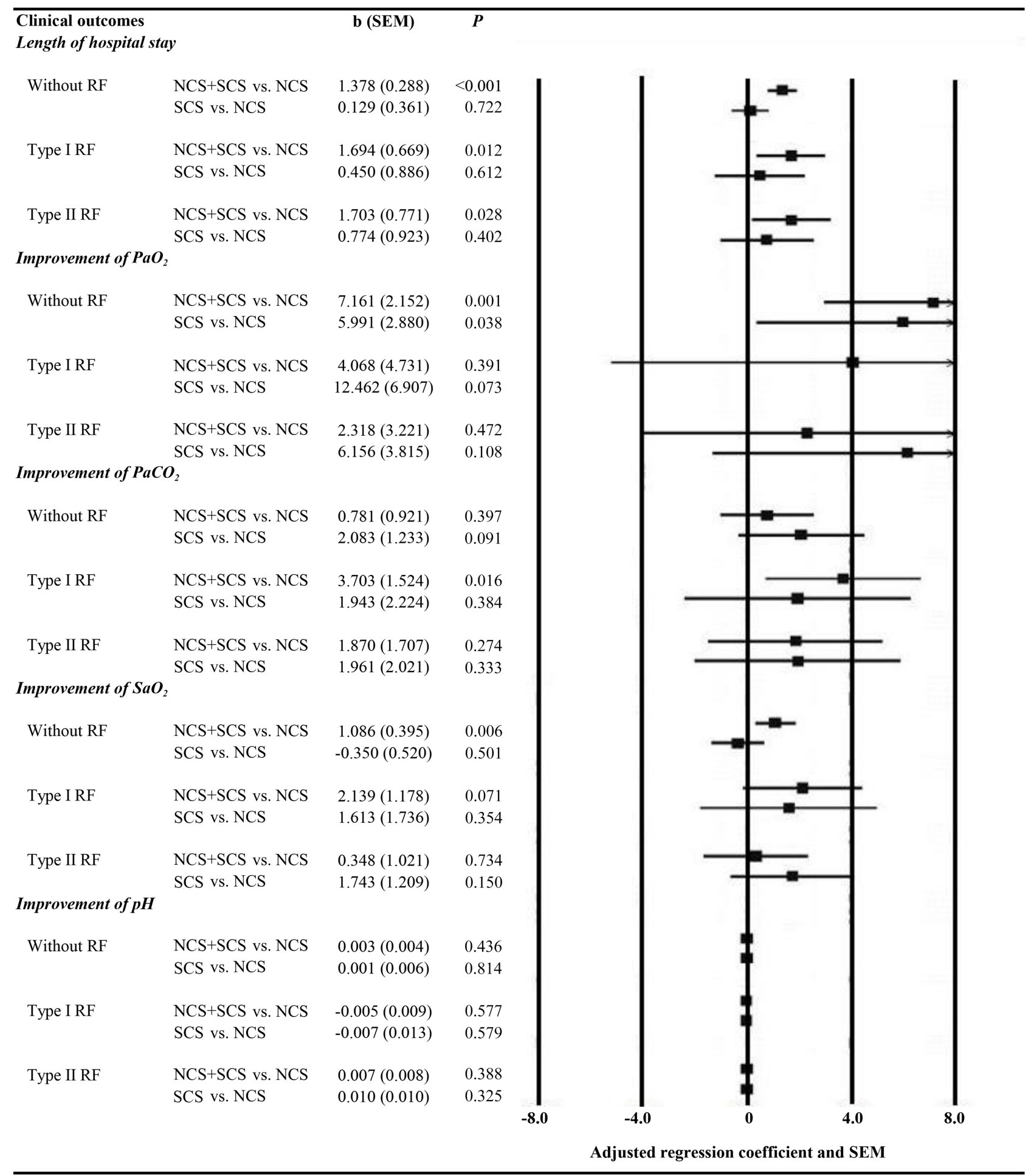

Figure 3 The final general linear model results for continuous data of clinical outcomes. NCS was used as the reference; the adjusted regression coefficient was adjusted by age, sex, height, weight, duration of COPD, duration of initial AECOPD, $\mathrm{PaO}_{2}$ at the first time, $\mathrm{PaCO}_{2}$ at the first time, $\mathrm{SaO}$ at the first time and PH at the first time. The value greater than 8 or less than -8 was not shown in the graph on the right.

Abbreviations: NCS, nebulized corticosteroids (budesonide); SCS, systemic corticosteroids; NCS+SCS, combination of NCS and SCS therapies; RF, respiratory failure; b, regression coefficient; SEM, standard error of the mean.

differences in symptoms, pulmonary function, and arterial blood gas analysis between the nebulized budesonide (2 $\mathrm{mg}, 3$ times/day) group and the intravenous methylprednisolone group (40 mg/day), while the occurrence of adverse events in the nebulized budesonide group was lower. ${ }^{22}$ Since the effect of AECOPD severity on 
Table 3 Clinical Outcomes of Hospitalized AECOPD Patients without RF After Propensity Score Matching

\begin{tabular}{|c|c|c|c|c|}
\hline \multirow[t]{3}{*}{ Clinical Outcomes } & \multicolumn{3}{|l|}{ Without RF } & \multirow{3}{*}{$P$} \\
\hline & NCS & SCS & NCS+SCS & \\
\hline & $(N=468)$ & $(N=3 \mid 7)$ & $(N=826)$ & \\
\hline \multicolumn{5}{|l|}{ Primary outcomes } \\
\hline Length of hospital stay (days) & $11.6 \pm 7.86$ & $\mid \mathrm{I} .4 \pm 4.6 \mathrm{I}$ & $13.3 \pm 6.69$ & $<0.001^{\mathrm{a}}$ \\
\hline Mortality & $5(1.1 \%)$ & $6(1.9 \%)$ & $10(1.2 \%)$ & $0.565^{c}$ \\
\hline Improvement of $\mathrm{PaO}_{2}(\mathrm{mmHg})$ & $-6.3 \pm 32.77$ & $-5.5 \pm 44.02$ & $-4.8 \pm 37.11$ & $0.913^{\mathrm{a}}$ \\
\hline Improvement of $\mathrm{PaCO}_{2}(\mathrm{mmHg})$ & $-5.4 \pm 15.62$ & $-4.0 \pm 17.13$ & $-5.0 \pm 14.00$ & $0.78 I^{\mathrm{a}}$ \\
\hline Improvement of $\mathrm{SaO}_{2}(\%)$ & $-0.7 \pm 4.32$ & $-1.5 \pm 6.55$ & $0.0 \pm 5.77$ & $0.050^{\mathrm{a}}$ \\
\hline Improvement of $\mathrm{pH}$ & $0.0 \pm 0.08$ & $0.0 \pm 0.09$ & $0.0 \pm 0.07$ & $0.850^{\mathrm{a}}$ \\
\hline \multicolumn{5}{|l|}{ Secondary outcomes } \\
\hline Intubation rate & $10(2.1 \%)$ & $9(2.8 \%)$ & $12(1.5 \%)$ & $0.291^{b}$ \\
\hline New onset pneumonia in hospital & $9(1.9 \%)$ & $13(4.1 \%)$ & $25(3.0 \%)$ & $0.201^{b}$ \\
\hline Rate of pneumoniaimprovement at discharge ${ }^{\#}$ & $110(23.5 \%)$ & $69(21.8 \%)$ & $219(26.5 \%)$ & $0.618^{c}$ \\
\hline Hospitalization expense (CNY) & $13,268.9 \pm 15,582.72$ & $13,752.9 \pm 8877.18$ & $\mid 7,669.9 \pm 14,380.95$ & $<0.001^{\mathrm{a}}$ \\
\hline
\end{tabular}

Notes: Data were summarized as mean \pm standard deviation for continuous variables and $\mathrm{n}$ (percentage) for categorical data. ${ }^{\#}$ Rate of pneumonia improvement at discharge was defined as the reduction in the incidence of pneumonia from baseline to discharge. ${ }^{\mathrm{a}}$ One-way analysis of variance. ${ }^{\mathrm{b}} \mathrm{Chi}$-square test. ${ }^{\mathrm{C}} \mathrm{Fisher}$ 's exact test.

Abbreviations: RF, respiratory failure; NCS, nebulized corticosteroids; SCS, systemic corticosteroids; AECOPD, acute exacerbation of chronic obstructive pulmonary disease; BMI, body mass index; CNY, China Yuan.

these results cannot be excluded, the conclusions of those studies are of limited value.

This is the first multicenter, non-interventional, realworld study to evaluate the effectiveness of NCS, SCS, and NCS+SCS therapies in the management of AECOPD in China, with a large sample size covering a large proportion of the country. PSM and subgroup analyses based on the presence of RF were used to reduce the impact of the potential confounding factors on the results of the study, especially AECOPD severity. Regardless of the severity of AECOPD assessed by RF, the three treatment groups after PSM were similar with respect to the improvement of blood gas analysis, intubation rates, and mortality. The NCS+SCS group showed significantly greater lengths of hospital stay in patients without RF as well as in patients with type I RF, and had greater hospitalization costs in patients without RF. The present study further confirms and expands the previous study, revealing that NCS, SCS, and NCS+SCS for AECOPD at the same severity level are similar with regard to intubation rates, in-hospital mortality, and changes in arterial blood gases in a real-world clinical setting in China, except for the fact that NCS + SCS was associated with increased risk of longer hospital stay and higher hospitalization costs. The results suggested that NCS is not inferior to SCS in effectiveness for these outcomes when used for the treatment of AECOPD. Therefore, we speculate that NCS may be an alternative to SCS, and it is possible to be used as the initial treatment of AECOPD in China. Nevertheless, some patients were treated with NCS+SCS after NCS or SCS failed. Thus, they needed longer observation time, leading to a prolonged hospital stay. This could explain why the NCS+SCS group had the longest length of hospital stay.

The results of the present study before PSM suggest that in patients with RF, the risks associated with SCS are more important than their potential benefits. A small study indicated that SCS in patients improved respiratory functions in patients with respiratory failure compared with placebo, but no comparison was made with $\mathrm{ICS}^{23}$ In addition, non-negligible adverse reactions were noted with SCS, including hyperglycemia, acute psychosis, and upper gastrointestinal hemorrhage. ${ }^{23}$ Furthermore, a negative relation between respiratory muscle strength and cumulative dose of SCS has been reported, ${ }^{24}$ highlighting the particular care that should be taken with SCS in patients with AECOPD and respiratory failure. In fact, two studies suggested that the use of SCS, particularly at high doses and with long duration, in patients with AECOPD and respiratory failure, will not help the patients survive their AECOPD event. ${ }^{25,26}$ A previous study in China showed that the most common daily dose of methylprednisolone injection was $40 \mathrm{mg}$, followed by $80 \mathrm{mg}$ and $20 \mathrm{mg}$, while the most common daily dose of oral methylprednisolone was $20 \mathrm{mg}$, followed by $16 \mathrm{mg}$ and $8 \mathrm{mg}$; in 
Table 4 Clinical Outcomes of Hospitalized AECOPD Cases with RF After Propensity Score Matching

\begin{tabular}{|c|c|c|c|c|c|c|c|c|}
\hline \multirow[t]{3}{*}{ Clinical Outcomes } & \multicolumn{4}{|l|}{ Type I RF } & \multicolumn{3}{|l|}{ Type II RF } & \multirow{3}{*}{$P$} \\
\hline & \multirow{2}{*}{$\begin{array}{l}\text { NCS } \\
(N=50)\end{array}$} & \multirow{2}{*}{$\begin{array}{l}\text { SCS } \\
(N=33)\end{array}$} & \multirow{2}{*}{$\begin{array}{l}\begin{array}{l}\text { NCS } \\
+S C S\end{array} \\
(N=73)\end{array}$} & \multirow[t]{2}{*}{$\mathbf{P}$} & \multirow{2}{*}{$\begin{array}{l}\text { NCS } \\
(N=80)\end{array}$} & \multirow{2}{*}{$\begin{array}{l}\text { SCS } \\
(N=67)\end{array}$} & \multirow{2}{*}{$\begin{array}{l}\begin{array}{l}\text { NCS } \\
+S C S\end{array} \\
(N=\mid 45)\end{array}$} & \\
\hline & & & & & & & & \\
\hline \multicolumn{9}{|l|}{ Primary outcomes } \\
\hline Length of hospital stay (days) & $11.3 \pm 4.95$ & $12.0 \pm 4.86$ & $13.8 \pm 5.60$ & $0.022^{\mathrm{a}}$ & $11.8 \pm 5.62$ & $12.6 \pm 4.67$ & $\mid 3.3 \pm 6.81$ & $0.208^{2}$ \\
\hline Mortality & $3(6.0 \%)$ & $\mathrm{I}(3.0 \%)$ & $2(2.7 \%)$ & $0.763^{b}$ & $0(0 \%)$ & $0(0 \%)$ & $4(2.8 \%)$ & $0.186^{t}$ \\
\hline Improvement of $\mathrm{PaO}_{2}(\mathrm{mmHg})$ & $16.8 \pm 23.74$ & $24.1 \pm 18.86$ & $21.1 \pm 27.07$ & $0.640^{\mathrm{a}}$ & $21.3 \pm 20.91$ & $29.0 \pm 25.89$ & $24.5 \pm 23.44$ & $0.241^{2}$ \\
\hline Improvement of $\mathrm{PaCO}_{2}(\mathrm{mmHg})$ & $3.5 \pm 9.54$ & $2.2 \pm 6.13$ & $3.4 \pm 8.69$ & $0.875^{a}$ & $-8.6 \pm 14.22$ & $-8.3 \pm 15.66$ & $-5.1 \pm|4.8|$ & $0.243^{\circ}$ \\
\hline Improvement of $\mathrm{SaO}_{2}(\%)$ & $6.3 \pm 11.85$ & $8.0 \pm 10.53$ & $6.5 \pm 7.04$ & $0.842^{\mathrm{a}}$ & $14.7 \pm 12.69$ & $13.8 \pm 13.54$ & $9.9 \pm 12.26$ & $0.053^{\circ}$ \\
\hline Improvement of $\mathrm{pH}$ & $0.0 \pm 0.07$ & $0.0 \pm 0.04$ & $0.0 \pm 0.05$ & $0.928^{\mathrm{a}}$ & $0.0 \pm 0.06$ & $0.0 \pm 0.08$ & $0.0 \pm 0.07$ & $0.483^{\circ}$ \\
\hline \multicolumn{9}{|l|}{ Secondary outcomes } \\
\hline Intubation rate & $2(4.0 \%)$ & $0(0 \%)$ & $2(2.7 \%)$ & $0.819^{\mathrm{b}}$ & $6(7.5 \%)$ & I (I.5\%) & $8(5.5 \%)$ & $0.253^{\mathrm{t}}$ \\
\hline New onset pneumonia in hospital & $0(0 \%)$ & I (3.0\%) & I (I.4\%) & $0.488^{\mathrm{b}}$ & $2(2.5 \%)$ & $\mathrm{I}(\mathrm{I} .5 \%)$ & $3(2.1 \%)$ & $1.000^{\mathrm{b}}$ \\
\hline $\begin{array}{l}\text { Rate of pneumoniaimprovement at } \\
\text { discharge }\end{array}$ & $8(16.0 \%)$ & $10(30.3 \%)$ & $12(16.4 \%)$ & - & $9(11.3 \%)$ & $16(23.9 \%)$ & $24(16.6 \%)$ & $0.451^{t}$ \\
\hline \multirow[t]{2}{*}{ Hospitalization expense (CNY) } & $14,992.1$ & $14,436.0$ & $18,250.8$ & $0.205^{\mathrm{a}}$ & $17,793.8$ & $17,3 \mid 2.2$ & $18,956.9$ & $0.687^{\circ}$ \\
\hline & $\pm 12,627.63$ & \pm 7168.92 & $\pm 13,433.27$ & & $\pm 16,916.03$ & $\pm 10,060.92$ & $\pm|3,8| 4.30$ & \\
\hline
\end{tabular}

Notes: Data were summarized as mean \pm standard deviation for continuous variables and $\mathrm{n}$ (percentage) for categorical data. Type I RF was defined as $\mathrm{PaO} \mathrm{O}_{2}<60 \mathrm{mmHg}$, with a normal or low $\mathrm{PaCO}_{2}$. Type II RF was defined as $\mathrm{PaO}_{2}<60 \mathrm{mmHg}$ and $\mathrm{PaCO}_{2}>50 \mathrm{mmHg}$. ${ }^{\#}$ Rate of pneumonia improvement at discharge was defined as the reduction in the incidence of pneumonia from baseline to discharge. ${ }^{\mathrm{a}}$ One-way analysis of variance. ${ }^{\mathrm{b}}$ Fisher's exact test.

Abbreviations: RF, respiratory failure; NCS, nebulized corticosteroids; SCS, systemic corticosteroids; AECOPD, acute exacerbation of chronic obstructive pulmonary disease; BMI, body mass index; CNY, China Yuan.

comparison, the most common daily dose of nebulized budesonide was $2 \mathrm{mg}$, followed by $4 \mathrm{mg}$ and $6 \mathrm{mg} .{ }^{15} \mathrm{In}$ this previous study, the mean length of hospitalization was $12.2 \pm 6.2$ days and the mortality rate during hospitalization was $1.2 \% .^{15}$ In the present study, the dose of corticosteroids was of course lower in the NCS group compared with the two other groups, but the duration of treatment was similar. Future studies should examine predictors that could help determine the most appropriate routes of administration, doses, and duration.

The present study is the first multicenter study to evaluate the effectiveness of steroid therapies for patients with AECOPD in China. The large sample size and stratification of AECOPD severity, according to RF, reduced the potential bias. Nevertheless, this study also has several limitations. First, since this is a retrospective real-world study, we could not define the baseline severity of COPD as well as comparing the effectiveness of NCS, SCS, and NCS+SCS on patients' lung functions due to incomplete data. Further analysis has been done based on the RF type as severity grade. Second, the dosage and duration of corticosteroids were not included in the multivariable analysis, which also can affect the outcome. Third, data of oxygen therapy was not collected in the database, which might have an impact on
$\mathrm{PaCO}_{2}$. Fourth, this was a retrospective study of data collected at multiple hospitals. Because different hospitals use different charts system and have different local practices and policies, some data could not be unified among centers. The types of exacerbations (ie, bacterial, viral etiology, eosinophilic) and biomarkers are among the variables that could not be analyzed. Previous studies reported that the cause of exacerbations is associated with treatment and patient outcomes. ${ }^{27-30}$ This will have to be examined in welldesigned and well-planned prospective registry studies. Fifth, almost all patients ( $>90 \%$ at each center) were treated with antibiotics, and we could not perform any reliable analysis of the impact of concomitant antibiotics use.

\section{Conclusions}

In conclusion, this post hoc analysis examined the NCS, SCS, and NCS+SCS therapies in AECOPD management in China. The real-world data do not demonstrate that NCS is worse than SCS, and NCS may be used as an alternative treatment for AECOPD.

\section{Abbreviations}

AECOPD, Acute exacerbations of chronic obstructive pulmonary disease; NCS, Nebulized corticosteroids; ICS, 
Inhaled corticosteroids; SCS, Systemic corticosteroids; PSM, Propensity score matching; RF, Respiratory failure; BMI, Body mass index; CNY, China Yuan; OR, Odds ratio; HR, Hazard ratio; b, Regression coefficient; SEM, Standard error of the mean.

\section{Data Sharing Statement}

The datasets used and/or analyzed during the current study are available from the corresponding author on reasonable request.

\section{Ethics Approval and Informed Consent}

This study was approved by the local ethics committees (Appendix 1) and conducted in accordance with the Declaration of Helsinki. Treatments were formulated according to local clinical practice, which presented a minimal risk to the patients. Informed consent was waived by the local ethics committees, as data were collected retrospectively from patients who have been treated and discharged from the hospital. The data accessed complied with relevant data protection and privacy regulations, as per Chinese laws and regulations and the Good Clinical Practice.

\section{Author Contributions}

All authors made a significant contribution to the work reported, whether that is in the conception, study design, execution, acquisition of data, analysis, and interpretation, or in all these areas; took part in drafting, revising or critically reviewing the article; gave final approval of the version to be published; have agreed on the journal to which the article has been submitted; and agree to be accountable for all aspects of the work.

\section{Funding}

This study was funded by AstraZeneca, China. The study was also supported by National Natural Science Fund for Distinguished Young Scholars to JFX (81925001), Shanghai Leading Talent Program (No. 2016036 to JFX), the Project of the Shanghai Hospital Development Center (16CR3036A to JFX), and National Key R\&D Program of China (No.2018YFC1311900) to JPZ. AECOPD NIS provided all clinical data, which was analyzed by CONTAIN members. AECOPD NIS was conducted by a large team of investigators (see details in the Appendix 2 collaborators list).

\section{Disclosure}

Jinping Zheng reports personal fees from AstraZeneca, during the conduct of the study. JFX and JPZ are in advisory boards of AstraZeneca and Boehringer Ingelheim. None of the other authors have a conflict of interest to declare for this work.

\section{References}

1. Yin $\mathrm{P}$, Wang $\mathrm{H}$, Vos $\mathrm{T}$, et al. A subnational analysis of mortality and prevalence of COPD in China from 1990 to 2013: findings from the global burden of disease study 2013. Chest. 2016;150:1269-1280. doi:10.1016/j.chest.2016.08.1474

2. Wang $\mathrm{C}, \mathrm{Xu} \mathrm{J}$, Yang $\mathrm{L}$, et al. Prevalence and risk factors of chronic obstructive pulmonary disease in China (the China Pulmonary Health $[\mathrm{CPH}]$ study): a national cross-sectional study. Lancet. 2018;391:1706-1717. doi:10.1016/S0140-6736(18) 30841-9

3. Vestbo J, Hurd SS, Agusti AG, et al. Global strategy for the diagnosis, management, and prevention of chronic obstructive pulmonary disease: GOLD executive summary. Am J Respir Crit Care Med. 2013;187:347-365. doi:10.1164/rccm.201204-0596PP

4. Mathers CD, Loncar D. Projections of global mortality and burden of disease from 2002 to 2030. PLoS Med. 2006;3:e442. doi:10.1371/ journal.pmed.0030442

5. Perera PN, Armstrong EP, Sherrill DL, Skrepnek GH. Acute exacerbations of COPD in the United States: inpatient burden and predictors of costs and mortality. COPD. 2012;9:131-141. doi:10.3109/ 15412555.2011.650239

6. Boulet LP. Asthma and obesity. Clin Exp Allergy. 2013;43:8-21. doi:10.1111/j.1365-2222.2012.04040.x

7. Donaldson GC, Seemungal TA, Patel IS, et al. Airway and systemic inflammation and decline in lung function in patients with COPD. Chest. 2005;128:1995-2004. doi:10.1378/chest.128. 4.1995

8. Walsh LJ, Wong CA, Oborne J, et al. Adverse effects of oral corticosteroids in relation to dose in patients with lung disease. Thorax. 2001;56:279-284. doi:10.1136/thorax.56.4.279

9. Dujovne CA, Azarnoff DL. Clinical complications of corticosteroid therapy. A selected review. Med Clin North Am. 1973;57:1331-1342. doi:10.1016/S0025-7125(16)32233-7

10. Brogden RN, McTavish D. Budesonide. An updated review of its pharmacological properties, and therapeutic efficacy in asthma and rhinitis. Drugs. 1992;44:375-407. doi:10.2165/00003495-19924403000007

11. Dompeling E, van Schayck CP, Molema J, et al. Inhaled beclomethasone improves the course of asthma and COPD. Eur Respir J. 1992;5:945-952.

12. Johansson SA, Andersson KE, Brattsand R, Gruvstad E, Hedner P. Topical and systemic glucocorticoid potencies of budesonide and beclomethasone dipropionate in man. Eur $J$ Clin Pharmacol. 1982;22:523-529. doi:10.1007/BF00609625

13. De Coster DA, Jones M. Tailoring of corticosteroids in COPD management. Curr Respir Care Rep. 2014;3:121-132. doi:10.1007/ s13665-014-0084-2

14. Sun X, He Z, Zhang J, et al. Compare the efficacy of inhaled budesonide and systemic methylprednisolone on systemic inflammation of AECOPD. Pulm Pharmacol Ther. 2015;31:111-116. doi:10. 1016/j.pupt.2014.09.004

15. Zhang J, Zheng J, Huang K, et al. Use of glucocorticoids in patients with COPD exacerbations in China: a retrospective observational study. Ther Adv Respir Dis. 2018;12:1753466618769514. doi:10.117 $7 / 1753466618769514$ 
16. Kiser TH, Allen RR, Valuck RJ, Moss M, Vandivier RW. Outcomes associated with corticosteroid dosage in critically ill patients with acute exacerbations of chronic obstructive pulmonary disease. Am $J$ Respir Crit Care Med. 2014;189:1052-1064. doi:10.1164/ rccm.201401-00580C

17. Lindenauer PK, Pekow PS, Lahti MC, et al. Association of corticosteroid dose and route of administration with risk of treatment failure in acute exacerbation of chronic obstructive pulmonary disease. JAMA. 2010;303:2359-2367. doi:10.1001/jama.2010.796

18. Vondracek SF, Hemstreet BA. Retrospective evaluation of systemic corticosteroids for the management of acute exacerbations of chronic obstructive pulmonary disease. Am J Health Syst Pharm. 2006;63:645-652. doi:10.2146/ajhp050316

19. Kiser TH, Sevransky JE, Krishnan JA, et al. Corticosteroid Dosing for Acute Exacerbations of Chronic Obstructive Pulmonary Disease Requiring Ventilatory Support. B23.WHEN I GET HOME: CONFRONTING THE CHALLENGES OF COPD EXACERBATION: American Thoracic Society. 2015;A2540-A2540

20. Hemenway AN, Terry AM. Evaluation of corticosteroid dose in acute exacerbation of chronic obstructive pulmonary disease. Hosp Pharm. 2017;52:546-550. doi:10.1177/0018578717722540

21. Maltais F, Ostinelli J, Bourbeau J, et al. Comparison of nebulized budesonide and oral prednisolone with placebo in the treatment of acute exacerbations of chronic obstructive pulmonary disease: a randomized controlled trial. Am J Respir Crit Care Med. 2002;165:698-703. doi:10.1164/ajrccm.165.5.2109093

22. Ding Z, Li X, Lu Y, et al. A randomized, controlled multicentric study of inhaled budesonide and intravenous methylprednisolone in the treatment on acute exacerbation of chronic obstructive pulmonary disease. Respir Med. 2016;121:39-47. doi:10.1016/j.rmed.2016. 10.013
23. Albert RK, Martin TR, Lewis SW. Controlled clinical trial of methylprednisolone in patients with chronic bronchitis and acute respiratory insufficiency. Ann Intern Med. 1980;92:753-758. doi:10.7326/00034819-92-6-753

24. Gayan-Ramirez G, Decramer M. Mechanisms of striated muscle dysfunction during acute exacerbations of COPD. J Appl Physiol. 2013;114:1291-1299. doi:10.1152/japplphysiol.00847.2012

25. Gunen H, Hacievliyagil SS, Kosar F, et al. Factors affecting survival of hospitalised patients with COPD. Eur Respir J. 2005;26:234-241. doi:10.1183/09031936.05.00024804

26. Funk GC, Bauer P, Burghuber OC, et al. Prevalence and prognosis of COPD in critically ill patients between 1998 and 2008. Eur Respir J. 2013;41:792-799.

27. Papi A, Luppi F, Franco F, Fabbri LM. Pathophysiology of exacerbations of chronic obstructive pulmonary disease. Proc Am Thorac Soc. 2006;3:245-251. doi:10.1513/pats.200512-125SF

28. Bafadhel M, McKenna S, Terry S, et al. Blood eosinophils to direct corticosteroid treatment of exacerbations of chronic obstructive pulmonary disease: a randomized placebo-controlled trial. Am J Respir Crit Care Med. 2012;186:48-55. doi:10.1164/rccm.201108-1553OC

29. Bafadhel M, McKenna S, Terry S, et al. Acute exacerbations of chronic obstructive pulmonary disease: identification of biologic clusters and their biomarkers. Am J Respir Crit Care Med. 2011;184:662-671. doi:10.1164/rccm.201104-0597OC

30. Mathioudakis AG, Janssens W, Sivapalan P, et al. Acute exacerbations of chronic obstructive pulmonary disease: in search of diagnostic biomarkers and treatable traits. Thorax. 2020;75:520-527.

\section{Publish your work in this journal}

The International Journal of COPD is an international, peer-reviewed journal of therapeutics and pharmacology focusing on concise rapid reporting of clinical studies and reviews in COPD. Special focus is given to the pathophysiological processes underlying the disease, intervention programs, patient focused education, and self management protocols. This journal is indexed on PubMed Central, MedLine and CAS. The manuscript management system is completely online and includes a very quick and fair peer-review system, which is all easy to use. Visit http://www.dovepress.com/testimonials.php to read real quotes from published authors. 